\title{
Brightness of melanin-based plumage coloration is a cue to oxidative stress in Himalayan Black Bulbuls (Hypsipetes leucocephalus nigerrimus)
}

Hsin-Yi Hung and Shou-Hsien Li*

\begin{abstract}
Background: Melanin-based coloration is often found to be associated with variations in physiological and behavioral traits that are essential in avian communication. However, the function of melanin-based traits to their bearers has been investigated less than that of carotenoid-based ones. It is commonly believed that expression of melanin-based pigmentation is genetically controlled. However, whether it could be modulated by physical condition has remained controversial. In this study, we demonstrate that the level of melanin-based plumage pigmentation could be negatively correlated with an individual's oxidative stress level.
\end{abstract}

Methods: In this study, we used two groups of Black Bulbuls (Hypsipetes leucocephalus nigerrimus) obtained from a pet-shop in 2010 and 2011 to examine the correlation between the melanin-based plumage coloration and the ratio of lymphocytes to heterocytes, which is an indicator of the oxidative stress experienced by an individual.

Results: We found a negative correlation between oxidative stress levels and expression of melanin-based pigmentation on the breast and scapular feathers, but the correlation only appeared in the 2011 group, individuals of which had higher oxidative stress level and brighter plumage (i.e. more melanins) than those of the 2010 group.

Conclusions: Our data suggest that melanin-based plumage could reflect an individual's physical condition in certain situations. Therefore, melanin-based plumage coloration could have a function in Himalayan Black Bulbuls' communication.

Keywords: Himalayan Black Bulbuls, Hypsipetes leucocephalus nigerrimus, Melanin-based trait, Oxidative stress

\section{Background}

Integumentary coloration is essential in avian communication: signalers use coloration to provide information, such as the bearer's physical condition or genetic quality, to receivers (Hill 2006; Senar 2006). Melanins, mainly responsible for black (eumelanins) or reddish and brown (pheomelanin) colors, are considered one of the main pigment classes associated with variations in the physiological and behavioral traits that are typical targets in animal communication. It has been shown that vertebrates

*Correspondence: t43028@ntnu.edu.tw

Department of Life science, National Taiwan Normal University, 88 Ting-Chow Rd, Sec 4, Taipei, Taiwan with melanin-richer coloration are more aggressive, sexually attractive and resistant to stress than those with melanin-lesser ones (Ducrest et al. 2008). However, compared with the well-studied carotenoid-based coloration, the function of melanin-based traits to their bearers is less understood.

Animals can synthesize melanins from the aromatic amino acids, phenylalanine and tyrosine. Melanization can be highly heritable (Hill and McGraw 2006; Jawor and Breitwisch 2003). In the past, variations in melaninbased traits were believed mainly to be genetically controlled (Bize et al. 2006). However, later studies suggest that these traits could be condition-dependent: factors such as parasitic infections and diet quality can also 
influence the level of expression of melanin-based signals (e.g., Fargallo et al. 2007; Jacquin et al. 2011). In particular, oxidative stress could play a critical role in regulating melanization (e.g., Roulin et al. 2008). High oxidative stress, which results from the imbalance between the rate of production of reactive oxygen species (including free radicals) by cell metabolism and the state of repair and antioxidant machinery, can induce ageing and reduce life span (Finkel and Holbrook 2000). The process of melanization could reduce the concentration of free radicals, making melanin an important antioxidant (Ducrest et al. 2008). However, the correlation between oxidative stress levels and the coloration of melanin-based traits is still controversial in birds (e.g., Ducrest et al. 2008; Galván and Alonso-Alvarez 2009). In the current study, we examined the correlation between the brightness of black plumage (defined in materials and methods below) and individuals' oxidative stress levels in Himalayan Black Bulbuls (Hypsipetes leucocephalus nigerrimus) to test whether melanin-based plumage could be an indicator of the individuals' physical condition.

To human eyes, melanin-based ornaments are usually just dull colored (i.e. black or brown), and are less varied within and between species than carotenoid-based ornaments (Badyaev and Hill 2000). However, the extra cones and oil drops that birds have make them have better at color discrimination than humans (Griffith et al. 2006; Jawor and Breitwisch 2003; McGraw 2006). Traditionally, avian melanin-based plumage patterns are characterized by patch size or darkness ranked by human eyes (e.g., Bize et al. 2006), but such methods may highly underestimate variations in brightness, and severely hamper our understanding of the functions of melanin-based traits. Fortunately, with the aid of a spectrometer, subtle differences in brightness of melanin-based pigments can be quantified, and results indicate that the variation in melanin-based coloration within and between species can be huge (McGraw et al. 2005).

The Himalayan Black Bulbul is widely distributed in Taiwan's broad-leaf forests at elevations from 100 to $1500 \mathrm{~m}$. Their plumage coloration is entirely melaninbased; black plumage with grey patches on the scapular feathers and remige. It makes the Himalayan Black Bulbul a perfect system to investigate the function of melanin-based signaling. In theory, the process of melanin production should reduce the sensitivity of the stressregulation processes and result in lower oxidative stress (Ducrest et al. 2008); therefore, we expected a negative correlation between an individual's oxidative stress levels and its black plumage coloration, with brighter individuals (i.e. more melanins) under lower oxidative stress. The results of this study should enhance our knowledge of the role of melanin-based coloration in avian communication.

\section{Methods}

\section{Study species and captive setting}

In total, 18 and 48 Himalayan Black Bulbuls were bought from a pet-shop in Taipei in 2010 and 2011 respectively. Each bird was housed individually in the laboratory. We collected $150 \mu \mathrm{L}$ blood from each individual for molecular sex typing. A drop of blood, approximately $5 \mu \mathrm{L}$, from each bird was used as the blood smear for the oxidative stress test. Each bird's brightness measurement and oxidative stress test were carried out in March of 2010 or 2011, which was the beginning of the breeding season.

\section{Molecular sex typing}

Gross DNA was extracted from blood samples with traditional proteinase $\mathrm{K}$ digestion followed by $\mathrm{LiCl}$ extraction [modified from the procedure of Gemmell and Akiyama (1996)]. Extracted DNA was re-suspended in $\mathrm{ddH}_{2} \mathrm{O}$ and stored at $-20^{\circ} \mathrm{C}$. Less than $100 \mathrm{ng}$ of genomic DNA was added to $12.5 \mu \mathrm{L}$ of PCR (polymerase chain reaction) mix containing $0.5 \mathrm{mmol} / \mathrm{L}$ of each of the dNTPs, $0.3 \mu \mathrm{mol} / \mathrm{L}$ of each PCR primer $(2550 \mathrm{~F} / 2718 \mathrm{R}$, Fridolfsson and Ellegren 1999), $10 \mathrm{mmol} / \mathrm{L}$ Tric-HCL, $50 \mathrm{mmol} / \mathrm{L} \mathrm{KCL}$, $1.5 \mathrm{mmol} / \mathrm{L}$ of $\mathrm{MgCl}_{2}$ and $0.4 \mathrm{U}$ of Taq DNA polymerase (Amersham Biosciences). The PCR profile was $94{ }^{\circ} \mathrm{C}$ for $3 \mathrm{~min}$, followed by 40 cycles of $95{ }^{\circ} \mathrm{C}$ for $20 \mathrm{~s}, 46^{\circ} \mathrm{C}$ for $30 \mathrm{~s}$ and $72{ }^{\circ} \mathrm{C}$ for $40 \mathrm{~s}$, finishing at $72{ }^{\circ} \mathrm{C}$ for $2 \mathrm{~min}$. The PCR reactions were carried out in iCyclers (Bio-Rad, Hercules, CA, USA). After the PCR reactions, we conducted electrophoresis with $1.2 \%$ agarose gel to determine the birds' sex. We identified eight females and ten males in 2010 and 18 females and 30 males in 2011.

\section{Brightness measurements}

For each individual, the reflectance of eight regions of melanin-based plumage- including the forehead, nape, back, breast, belly, tail, remige and scapular featherswas measured using an USB2000 spectrometer (Ocean Optics) with a HL2000 deuterium-halogen light source (Ocean Optics). A R600-7-UV/125F probe (Ocean Optics) was held perpendicular to the surface of the feathers with a cylindrical cap at the end to standardize the distance $(5 \mathrm{~mm})$ measured and to shield ambient light. To calculate relative reflectance, a white standard (Labsphere) was used. To collect the dark reference, the light source was capped by a black plastic plate. Each part was measured three times to calculate repeatability (repeatability $>90 \%$, Lessells and Boag 1987). The brightness of each region was defined as the average of total reflectance within the range of $300-700 \mathrm{~nm}$. McGraw 
et al. (2005) demonstrated that the concentrations of both eumelain and phaeomelanin in feathers were significantly and positively correlated with brightness: a brighter measurement indicates more melanin in the feathers.

\section{Oxidative stress test}

We calculated the ratio of lymphocytes $(L)$ to heterocytes $(H)$ in total of 100 leukocytes as a measure of oxidative stress for each individual bulbul following the methods used by Vleck et al. (2000). The blood smear was first dyed with a Wright-Giemsa stain for $3 \mathrm{~min}$ and then with $5 \%$ PBS for $70 \mathrm{~s}$. After drying, the numbers of lymphocytes and heterocytes were counted under a microscope at a magnification of $100 \times$ with oil immersion, and the $H / L$ ratio calculated. The $H / L$ ratio has been proved to be a good indicator of oxidative stress: higher levels of corticosterones can cause higher oxidative stress and also increase the number of heterocytes in the blood (Davis et al. 2008; Gross and Siegel 1983). Because leukocyte numbers change more slowly in response to stress than corticosterone does (Maxwell 1993), H/L ratios provide a more useful and accurate measure of long-term stress than a single measure of plasma corticosterone (McFarlane and Curtis 1989; Vleck et al. 2000).

\section{Statistical analysis}

Two-way ANOVA was conducted to test whether each individual's oxidative stress level and the brightness of each its body parts differed significantly between years. In these tests, sex, year and the interaction between sex and year were taken into account. Multiple regression was used to test whether the brightness of each body part correlated with oxidative stress $(H / L$ ratio) while taking into account the birds' sex and the interaction between sex and oxidative stress. In the tests, the $H / L$ ratio was log transformed to fit the normal distribution.

\section{Ethics statement}

Live birds were housed in the Animal Care House of the National Taiwan Normal University and cared for using procedures approved by the Institutional Animal Care and Use Committee of the Department of Life Science (IACUC Approval No 96026).

\section{Results}

The average $H / L$ ratio in 2010 was $0.35 \pm 0.05$ and ranged from 0.1 to 0.4 , while the average $H / L$ ratio in 2011 was $1.05 \pm 0.13$ and ranged from 0.2 to 4.6. Individuals in the 2010 group were under significantly lower oxidative stress (lower $H / L$ ratio) than those in the 2011 group (Fig. 1, two-way ANOVA, $F=15.36, p=0.0002$ ). The females' average $H / L$ ratio was $0.76 \pm 0.15$ and the males'

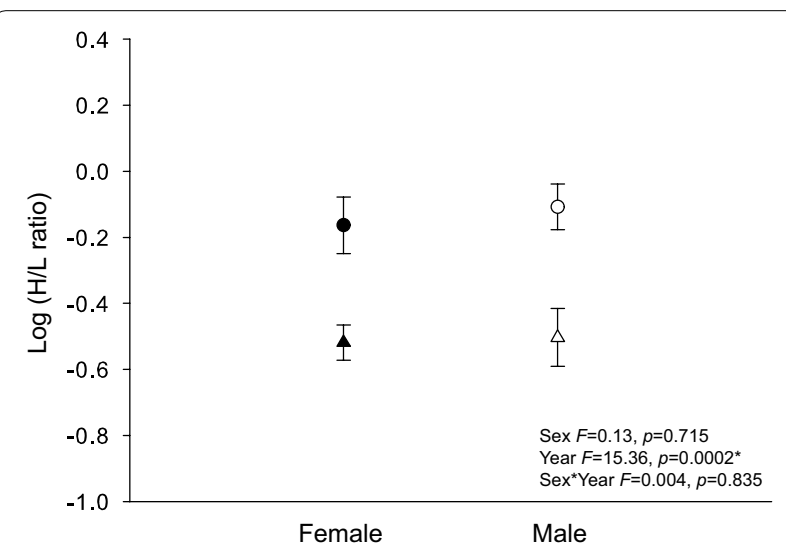

Fig. 1 The $\log (H / L$ ratio) of two sexes in different years. The circles indicate the average Log $(H / L)$ ratios for 2011 and the triangles indicate those for 2010. The lines indicate the standard error. The solid symbols represent the females and the hollow ones represent the males. Two-way ANOVA, factor year includes 2010 and 2011. df $=1$, ${ }^{*} p<0.05$

was $0.92 \pm 0.14$; there was no significant difference in the two sexes' $H / L$ ratios (Fig. 1, two-way ANOVA, $F=0.73$, $p=0.72)$.

The brightness of melanin-based colors differed significantly between Himalayan Black Bulbuls in the 2010 and 2011 groups. Members of the 2011 group were brighter (i.e. more melanins) than those of the 2010 group, mainly in belly (two-way ANOVA, Table 1; Ls mean \pm SE, 2010 group $4.45 \pm 0.31 \%, 2011$ group $5.34 \pm 0.19 \%$, post hoc (student's $t$ ) test, CL $-1.61 ;-0.1$ ) and breast (Table 1; 2010 group $3.22 \pm 0.21 \%$, 2011 group $3.82 \pm 0.13 \%$, post hoc (student's $t$ ) test, CL $-1.10 ;-0.11$ ). The same tendencies were observed at the remige and scapulars, although there were significant interactions with two factors, sex and year (two-way ANONA Table 1).

The results of multiple regression indicate that brighter breast and scapular feathers might be related to lower oxidative stress: there was a significant negative correlation between the brightness of breast and scapulars and oxidative stress (multiple regressions, Table 2; linear correlation coefficients in breast, $r_{\text {female }}=-0.23$, $r_{\text {male }}=-0.47$; correlations in scapulars, $r_{\text {female }}=-0.54$, $r_{\text {male }}=-0.23$ ), but not between oxidative stress and the brightness of the other six body parts. However, this relationship only applied in 2011 and not in 2010: the 2010 $H / L$ ratio was not significantly correlated with the brightness of any melanin-based parts (multiple regressions, Table 2).

\section{Discussion}

Our regression analysis for the 2011 sample shows that melanin-based characteristics could be brighter (i.e. 
Table 1 Two-way ANOVA tests of brightness in eight body parts

\begin{tabular}{llll}
\hline Parts & Source & F Ratio & $\boldsymbol{p}$ \\
\hline Back & Sex & 0.50 & 0.483 \\
& Year ${ }^{\text {a }}$ & 0.47 & 0.495 \\
Belly & Year $\times$ sex & 0.10 & 0.759 \\
& Sex & 0.01 & 0.921 \\
& Year & 5.84 & $0.019^{*}$ \\
Breast & Year $\times$ sex & 3.58 & 0.063 \\
& Sex & 0.89 & 0.350 \\
Forehead & Year & 6.05 & $0.017^{*}$ \\
& Year $\times$ sex & 0.11 & 0.738 \\
Nape & Sex & 1.84 & 0.181 \\
& Year & 0.80 & 0.375 \\
& Year $\times$ sex & 1.71 & 0.196 \\
Remige & Sex & 0.39 & 0.533 \\
& Year & 1.01 & 0.319 \\
& Year $\times$ sex & 0.61 & 0.439 \\
Tail & Sex & 2.61 & 0.112 \\
& Year & 7.95 & $0.007^{*}$ \\
& Year $\times$ sex & 5.27 & $0.025^{*}$ \\
& Sex & 3.75 & 0.057 \\
& Year & 13.58 & $0.001^{*}$ \\
& Year $\times$ sex & 4.68 & $0.035^{*}$ \\
& Sex & 1.95 & 0.168 \\
& Year & 2.18 & 0.145 \\
& Year $\times$ sex & 0.70 & 0.406 \\
\hline S & & & \\
& & &
\end{tabular}

$\mathrm{df}=1$

${ }^{*} p<0.05$

a Factor year: including 2010 and 2011

more melanin) in individuals that suffered lower oxidative stress. This result is consistent with the work of Ducrest et al. (2008). They reviewed six studies and discovered a significantly negative correlation between the expression of melanin-based characteristics and the level of oxidative stress. This implies that expression of melanin-based traits is condition-dependent and could be a quality cue reflecting an individual's physical condition (Hill and McGraw 2006).

However, individuals in our 2011 sample suffered higher oxidative stress than those in the 2010 sample but had brighter plumage (i.e. more melanins)-a positive correlation, contrasting with the negative correlation found within the 2011 group. Several recent studies also report similar, positive, correlations between oxidative stress and melanin-based coloration (Galván and AlonsoAlvarez 2008; Galván and Alonso-Alvarez 2009; Hõrak et al. 2010), suggesting that an alternative hypothesis about a different interaction between melanin coloration
Table 2 Multiple regressions of brightness in different body parts in 2010 and 2011

\begin{tabular}{|c|c|c|c|c|c|}
\hline \multirow[t]{2}{*}{ Parts } & \multirow[t]{2}{*}{ Terms } & \multicolumn{2}{|l|}{2010} & \multicolumn{2}{|l|}{2011} \\
\hline & & $t$ ratio & $p$ & $t$ ratio & $p$ \\
\hline \multirow[t]{4}{*}{ Back } & Intercept & 7.25 & $<.0001$ & 29.49 & $<.0001$ \\
\hline & $\operatorname{Sex}(F)$ & 0.25 & 0.808 & 0.83 & 0.413 \\
\hline & $\log (H / L \text { ratio })^{a}$ & -0.05 & 0.964 & -1.14 & 0.262 \\
\hline & $\operatorname{Sex}(F) \times \log (H / L$ ratio $)$ & -1.46 & 0.166 & -1.49 & 0.144 \\
\hline \multirow[t]{4}{*}{ Belly } & Intercept & 6.09 & $<.0001$ & 24.15 & $<.0001$ \\
\hline & $\operatorname{Sex}(F)$ & -1.37 & 0.194 & 1.53 & 0.134 \\
\hline & $\log (H / L$ ratio $)$ & 0.78 & 0.447 & -1.35 & 0.183 \\
\hline & $\operatorname{Sex}(F) \times \log (H / L$ ratio $)$ & -0.85 & 0.409 & 0.35 & 0.728 \\
\hline \multirow[t]{4}{*}{ Breast } & Intercept & 9.00 & $<.0001$ & 24.53 & $<.0001$ \\
\hline & $\operatorname{Sex}(F)$ & 0.65 & 0.525 & 0.93 & 0.358 \\
\hline & $\log (H / L$ ratio $)$ & 0.19 & 0.853 & -2.43 & $0.019^{*}$ \\
\hline & $\operatorname{Sex}(F) \times \log (H / L$ ratio $)$ & -1.44 & 0.172 & -0.46 & 0.645 \\
\hline \multirow[t]{4}{*}{ Forehead } & Intercept & 3.85 & 0.002 & 17.16 & $<.0001$ \\
\hline & $\operatorname{Sex}(F)$ & 1.52 & 0.150 & -0.02 & 0.984 \\
\hline & $\log (H / L$ ratio $)$ & -0.49 & 0.635 & -0.39 & 0.696 \\
\hline & $\operatorname{Sex}(F) \times \log (H / L$ ratio $)$ & -0.43 & 0.675 & 0.18 & 0.858 \\
\hline \multirow[t]{4}{*}{ Nape } & Intercept & 7.03 & $<.0001$ & 30.95 & $<.0001$ \\
\hline & $\operatorname{Sex}(F)$ & -0.75 & 0.465 & 0.01 & 0.995 \\
\hline & $\log (H / L$ ratio $)$ & 0.70 & 0.497 & -0.62 & 0.539 \\
\hline & $\operatorname{Sex}(F) \times \log (H / L$ ratio $)$ & 0.18 & 0.858 & -1.2 & 0.238 \\
\hline \multirow[t]{4}{*}{ Scapulars } & Intercept & 8.07 & $<.0001$ & 40.47 & $<.0001$ \\
\hline & $\operatorname{Sex}(F)$ & -2.22 & $0.043^{*}$ & 0.03 & 0.976 \\
\hline & $\log (H / L$ ratio $)$ & -1.01 & 0.329 & -2.37 & $0.022^{*}$ \\
\hline & $\operatorname{Sex}(F) \times \log (H / L$ ratio $)$ & -0.76 & 0.461 & -0.93 & 0.358 \\
\hline \multirow[t]{4}{*}{ Remige } & Intercept & 5.70 & $<.0001$ & 49.39 & $<.0001$ \\
\hline & $\operatorname{Sex}(F)$ & -2.41 & $0.032^{*}$ & 0.59 & 0.555 \\
\hline & $\log (H / L$ ratio $)$ & -0.67 & 0.515 & -0.28 & 0.782 \\
\hline & $\operatorname{Sex}(F) \times \log (H / L$ ratio $)$ & -1.60 & 0.133 & -0.78 & 0.440 \\
\hline \multirow[t]{4}{*}{ Tail } & Intercept & 6.23 & $<.0001$ & 27.93 & $<.0001$ \\
\hline & $\operatorname{Sex}(F)$ & 0.31 & 0.759 & 2.1 & $0.042^{*}$ \\
\hline & $\log (H / L$ ratio $)$ & 0.13 & 0.899 & 0.34 & 0.739 \\
\hline & $\operatorname{Sex}(F) \times \log (H / L$ ratio $)$ & 1.01 & 0.330 & -0.36 & 0.724 \\
\hline
\end{tabular}

${ }^{*} p<0.05$

${ }^{a}$ Heterocyte/lymphocyte ratio log transformed to normalize the distribution

and oxidative stress should be considered in the role of melanin-based signaling.

Glutathione (GSH), another key intracellular antioxidant, has been suggested to inhibit eumelanogenesis and eumelanin-based black ornaments, and might be crucial to the expression of melanin-based traits (Benedetto et al. 1982). GSH is a tripeptide thiol found in virtually all animal cells, and often considered as a vital antioxidant. It functions in the reduction of the disulfide linkages of proteins, in the synthesis of the deoxyribonucleotide precursors of DNA and in the protection of cells against 
free radicals (Meister 1983). GSH also serves as an agent regulating the process of melanogenesis. Low GSH levels have been associated with the deposition of melanin in bird feathers, whereas high GSH levels inhibit melanogenesis (Galván and Alonso-Alvarez 2008; Galván and Alonso-Alvarez 2009; Hõrak et al. 2010). Hence, GSH might be involved in a trade-off between antioxidants and melanogenesis. We suspect this might be the case in the Black Bulbuls: individuals in 2011 might have had lower GSH than those in 2010, therefore having brighter plumage but higher oxidative stress.

The fact that we only discovered a significant relationship in the 2011 group, not in the 2010 group, might also provide support for the GSH hypothesis. A study in rats suggested that corticosterone could decrease glutathione levels (Patel et al. 2002). In our study, individuals in 2011 suffered higher oxidative stress of those in 2010, a relatively lower level of GSH might be expected in 2011 than in 2010. A lower level of GSH could enhance the melanin concentration or the patch size of individuals' melanin-based ornaments (Galván and Alonso-Alvarez 2008; Galván and Alonso-Alvarez 2009; Hõrak et al. 2010). Therefore the positive correlation between oxidative stress and brightness of melanin-based traits in the 2 years would be expected.

In our study, individuals in 2011 suffered almost three times the oxidative stress of those in 2010; and variations in oxidative stress were larger within the 2011 group. Previous studies have shown that individuals' $H / L$ ratio usually keeps steady until it moves on to a different lifehistory stage: the individual's $H / L$ ratio could be higher at times during migration (Work et al. 1999), and parasitic infection or oil pollution can raise $H / L$ ratios to four to six times those of controls (Davis et al. 2008). Since we collected all data at the beginning of breeding seasons of 2010 or 2011 and after molting, individuals should been in the same stage of life-history in the 2 years. But unpublished data showed that there were different rates of parasitic infection in the 2 years (Hung collected): a higher percentage of malarial infection in 2011 (37\%) than in 2010 (26\%). Therefore, besides the level of GSH, the rate of malarial infection might be another factor causing different levels of oxidative stress in our study between 2 years. But this requires further investigation.

The status of oxidative stress we test here should not reflect the physical condition in real time or during molting, but is rather the long-term condition of an individual. Such long-term oxidative stress could be affected by many factors: genetic, environmental or different lifehistory stages (Monaghan et al. 2009). Therefore, Black Bulbuls might be able to use melanin-based coloration to evaluate individual's long-term physical condition. Consequently, the traits might be important in sexual selection or individual assessment in animal aggressive behavior in the Himalayan Black Bulbul. This hypothesis, however, requires further verification.

\section{Conclusion}

In summary, we examined the relationship between individuals' oxidative stress levels and expression of melaninbased plumage in Himalayan Black Bulbuls. Our data suggest that melanin-based plumage can reflect individuals' long-term physical condition in certain situations. Therefore we propose that the brightness of melaninbased plumage could have a role in Himalayan Black Bulbuls' communication.

\section{Authors' contributions}

$\mathrm{HYH}$ and SHL conceived and designed the experiments, and HYH performed the experiments. All the authors participated in the data analysis and paper writing. Both authors read and approved the final manuscript.

\section{Acknowledgements}

The project was founded by the Population Genetics Lab, Department of Life Science, National Taiwan Normal University. We thank the following for laboratory assistance: C-F Yen, R-W Chu and R-C Lin. We also thank Y-Z Yi and Z-R Hung for helping care for the birds. Specially, we thank A. Watson who provided English editing.

\section{Competing interests}

The authors declare that they have no competing interests

Received: 2 July 2015 Accepted: 15 October 2015

Published online: 23 December 2015

\section{References}

Badyaev AV, Hill GE. Evolution of sexual dichromatism: contribution of carotenoid-versus melanin-based coloration. Biol J Linn Soc. 2000;69:153-72.

Benedetto J-P, Ortonne J-P, Voulot C, Khatchadourian C, Prota G, Thivolet J. Role of thiol compounds in mammalian melanin pigmentation. II. Glutathione and related enzymatic activities. J Invest Dermatol. 1982;79:422-4.

Bize P, Gasparini J, Klopfenstein A, Altwegg R, Roulin A. Melanin-based coloration is a nondirectionally selected sex-specifec signal of offspring development in the Alpine swift. Evolution. 2006;60:2370-80.

Davis A, Maney D, Maerz J. The use of leukocyte profiles to measure stress in vertebrates: a review for ecologists. Funct Ecol. 2008;22:760-72.

Ducrest A-L, Keller L, Roulin A. Pleiotropy in the melanocortin system, coloration and behavioural syndromes. Trends Ecol Evol. 2008;23:502-10.

Fargallo JA, Laaksonen T, Korpimäki E, Wakamatsu K. A melanin-based trait reflects environmental growth conditions of nestling male Eurasian kestrels. Evol Ecol. 2007;21:157-71.

Finkel T, Holbrook NJ. Oxidants, oxidative stress and the biology of ageing. Nature. 2000;408:239-47.

Fridolfsson A-K, Ellegren H. A simple and universal method for molecular sexing of non-ratite birds. J Avian Biol. 1999;30:116-21.

Galván I, Alonso-Alvarez C. An intracellular antioxidant determines the expression of a melanin-based signal in a bird. PLoS One. 2008; $3:$ e3335.

Galván I, Alonso-Alvarez C. The expression of melanin-based plumage is separately modulated by exogenous oxidative stress and a melanocortin. Proc R Soc B. 2009;276:3089-97.

Gemmell NJ, Akiyama S. An efficient method for the extraction of DNA from vertebrate tissues. Trends Genet. 1996;12:338-9.

Griffith SC, Parker TH, Olson VA. Melanin-versus carotenoid-based sexual signals: is the difference really so black and red? Anim Behav. 2006;71:749-63. 
Gross W, Siegel $\mathrm{H}$. Evaluation of the heterophil/lymphocyte ratio as a measure of stress in chickens. Avian Dis. 1983;27:972-9.

Hõrak P, Sild E, Soomets U, Sepp T, Kilk K. Oxidative stress and information content of black and yellow plumage coloration: an experiment with greenfinches. J Exp Bio. 2010;213:2225-33.

Hill GE. Female mate choice for ornamental coloration. In: Hill GE, McGraw KJ, editors. Bird Coloration. Cambrige: Harvard University Press; 2006.

Hill G, McGraw K. Bird Coloration I: mechanisms and measurements. Cambridge: Harvard University Press; 2006.

Jacquin L, Lenouvel P, Haussy C, Ducatez S, Gasparini J. Melanin-based coloration is related to parasite intensity and cellular immune response in an urban free living bird: the feral pigeon Columba livia. J Avian Biol. 2011;42:11-5.

Jawor JM, Breitwisch R. Melanin ornaments, honesty, and sexual selection. Auk. 2003;120:249-65

Lessells C, Boag PT. Unrepeatable repeatabilities: a common mistake. Auk. 1987;104:116-21.

Maxwell M. Avian blood leucocyte responses to stress. World Poult Sci J. 1993:49:34-43.

McFarlane JM, Curtis SE. Multiple concurrent stressors in chicks. 3. Effects on plasma corticosterone and the heterophil: Iymphocyte ratio. Poult Sci. 1989:68:522-7.

McGraw K, Safran R, Wakamatsu K. How feather colour reflects its melanin content. Func Ecol. 2005;19:816-21.

McGraw KJ Mechanics of melanin-based coloration. In: Hill G, McGraw K (eds) Bird Coloration. Vol. I. mechanisms and measurement. Cambridge: Harvard University Press. 2006.
Meister A. Selective modification of glutathione metabolism. Science. 1983;220:472-7.

Monaghan P, Metcalfe NB, Torres R. Oxidative stress as a mediator of life history trade-offs: mechanisms, measurements and interpretation. Ecol Lett. 2009;12:75-92.

Patel R, McIntosh L, McLaughlin J, Brooke S, Nimon V, Sapolsky R. Disruptive effects of glucocorticoids on glutathione peroxidase biochemistry in hippocampal cultures. J Neurochem. 2002;82:118-25.

Roulin A, Almasi B, Rossi-Pedruzzi A, Ducrest A-L, Wakamatsu K, Miksik I, Blount JD, Jenni-Eiermann S, Jenni L. Corticosterone mediates the conditiondependent component of melanin-based coloration. Anim Behav. 2008;75:1351-8.

Senar JC. Color displays as intrasexual signals of aggression and dominance. In: Hill GE, McGraw KJ, editors. Bird coloration. Cambridge: Harvard University Press; 2006

Vleck CM, Vertalino N, Vleck D, Bucher TL. Stress, corticosterone, and heterophil to lymphocyte ratios in free-living Adelie penguins. Condor. 2000;102:392-400.

Work TM, Massey JG, Johnson L, Dougill S, Banko PC. Survival and physiologic response of Common Amakihi and Japanese White-eyes during simulated translocation. Condor. 1999;101:21-7.

\section{Submit your next manuscript to BioMed Central and take full advantage of:}

- Convenient online submission

- Thorough peer review

- No space constraints or color figure charges

- Immediate publication on acceptance

- Inclusion in PubMed, CAS, Scopus and Google Scholar

- Research which is freely available for redistribution

Submit your manuscript at

www.biomedcentral.com/submit

C Biomed Central 